\title{
A Message from the JTRF Co-General Editors
}

This issue launches a new year for $J T R F$, the sixth with our publisher - the Upper Great Plains Transportation Institute. The Spring 2009 issue contains the usual wide variety of contemporary transportation topics that distinguishes JTRF from the other transportation journals. Topics in this issue include the following:

- Economic feasibility of cellulosic ethanol

- Simulated ethanol transportation patterns and costs

- Motor carriers' and shippers' perceptions of carrier selection factors

- Effect of alternative winter highway maintenance operations on highway user mobility

- Impact of U.S.-EU open aviation treaty on U.S. aviation

- Effect of U.S. airline financial distress on customer service

- Transportation model validation

In "Derivation of Crop Residue Feedstock Supply Curves Using Geographic Information Systems," Hayk Khachatryan, Eric L. Jessup and Ken Casavant explore the economic feasibility of cellulosic ethanol processing in the state of Washington. The primary objective of the paper was to spatially analyze the collection and transportation costs of cellulosic feedstock using GIS Network Analyst extension. The farm gate cost, transportation costs (including loading and unloading), physical availability, and geographic distribution information was combined to derive feedstock supply curves. The authors concluded that the economic viability of the cellulosic ethanol industry depends on the delivered cost of feedstocks.

Wyatt Thompson and Seth Meyer jointly simulate consumer demand for ethanol and ethanol transportation costs in "Simulated Ethanol Transportation Patterns and Costs." The objective of the paper was to show how ethanol demand and transportation costs change for different benchmark oil and ethanol prices. Output was generated from a simulation model. The authors used a stylized model of ethanol demand and transport costs since the data don't exist to estimate key relationships. The authors focus on short term U.S. demand for ethanol produced in the Midwest, introducing constraints relating to E85 consumer adaption and infrastructure development that would be irrelevant in a long-run analysis. Thompson and Meyer found a non-linear relationship between benchmark prices for oil and ethanol and ethanol transportation costs.

In "The Similarity of Motor Carriers' and Shippers' Perceptions of the Carrier Choice Decision Improve," Shane R. Premeaux re-examines the perceived importance of 36 carrier selection variables to both motor carriers and shippers. The author conducted surveys in 2006 and 2008 using the same sample of traffic managers and motor carrier managers in both surveys. The carriers were asked their perceptions of the importance that shippers place on each of the 36 selection variables. Shippers were also asked to rate the importance of each selection variable. He found that shippers and carriers did not classify six selection variables similarly in the 2008 survey. However, this was an improvement over the nine significant differences in the 2006 survey. Premeaux found that carriers overestimated the importance of the same four variables in both surveys: carrier reputation, past performance, cooperation, and knowledge of shipper needs. He said results indicate that carriers now realize the importance of providing information, billing, and shipment tracing services through a comprehensive web-enhanced EDI, but they also need to focus on offering more flexible rates and responding effectively to emergency situations.

Jean-Claude Thill and Hai Sun compare the winter maintenance performance in the Buffalo, NY, area of the NewYork State Department of Transportation (NYSDOT) and the New York 
State Thruway Authority (NYSTA) in "Comparing Approaches to Winter Highway Maintenance Operations Through User Mobility Performance." The purpose of the paper was to determine if level of service (LOS) differences between NYSDOT and NYSTA can be detected during and after winter snow events, which could then be imputed to differences in snow and ice control measures. The authors used speed reduction during snow storms and the time taken for speed recovery after storm events as the two measures of LOS. The authors use multivariate linear regressions to model the two mobility indicators. Thill and Sun found major differences in the LOS between the two agencies, particularly in the early stages of a snow storm. They also found no difference in the road user speed recovery of the two agencies in the hour following the end of snow events. Finally, they concluded that NYSTA higher outlay of resources appears to be effective only during short storms and in the early stages of storms

In "Impact of U.S.-EU Open Aviation Area Treaty on U.S. Aviation: A Parametric Analysis with Simulation," Dipasis Bhadra and Roger Schaufele develop a framework to generate probabilistic forecasts for U.S.-EU air passenger traffic for the period 2008-2015. The objective of the paper is to measure the potential impact of the U.S.-EU Open Aviation Area (OAA) agreement on the magnitude of air travel in the U.S., with explicit attention to the uncertainty of air travel, and subsequent effect on network structure of the U.S. National Airspace System (NAS). The authors develop a parametric model to estimate and forecast air passenger flows. They introduce uncertainty into the model to benchmark the bounds of future air passenger travel between the U.S. and EU. In the parametric model the log of air passengers between EU countries and the U.S. is made a function of a weighted index of GDP of the U.S. and EU countries, inflation adjusted fare per mile, a bilateral treaty dummy variable, and a 9/11 dummy. All the explanatory variables are expressed in logs. Then the authors used MonteCarlo simulation to generate probabilistic forecasts of air passenger travel for U.S.-EU country pairs. The average annual projected growth rate of U.S.-EU air passengers for the $2012-2015$ period was projected to be $4.25 \%$

Dina Ribbink, Christian Hofer, and Martin Dresner investigate the effect of financial distress on three measures of U.S. airline customer service in "Airline Financial Distress and Customer Service." While previous research has examined how customer service affects financial performance, the authors investigate the opposite relationship of the impact of financial stress on customer service. The three indicators of customer service examined by the authors were on-time performance, reported mishandled bags per 1,000 passengers, and overbooking. The authors develop Seemingly Unrelated Regressions (SUR) where each of the service measures is a dependent variable and made a function of the same independent variables. The lagged Z-Score was used to measure financial distress of airlines, and other control variables that may affect customer service were included in the SUR. Ribbink, Hofer, and Dresner found that higher financial stress is associated with better ontime performance of airlines and fewer lost bags. The effect on the number of "bumped" passengers was non-significant.

In "Transportation Model Validation Using Extreme-World Method Scenario Construction," Heather Shar and co-authors develop a model validation approach to evaluate the Alabama Transportation Infrastructure Model (ATIM). The approach uses a scenario planning technique (extreme-world view) that allows model developers to test a wider range of model inputs rather than using limited current of historical data. The authors develop some scenarios using the extreme-world view and the scenarios are run in ATIM. The model's response to a range of scenarios indicates that it tracks expected real-world performance well.

Kofi Oberg

Co-General Editor-JTRF
Michael W. Babcock

Co-General Editor-JTRF 